\title{
Assessing the Influence of Soil-Reinforcement Interaction Parameters on the Performance of a Low Fill on Compressible Subgrade. Part II: Influence of Surface Maintenance
}

\author{
Ivonne A. M. G. Góngora ${ }^{1} \cdot$ Ennio M. Palmeira ${ }^{1}$
}

Received: 17 October 2015/Accepted: 16 December 2015/Published online: 26 December 2015

(C) Springer International Publishing Switzerland 2016

\begin{abstract}
Geosynthetics can be effectively used as reinforcement of low fills on weak subgrades, as is the case of unpaved roads. They can reduce fill deformation and increase its life. This paper investigates the performance of unreinforced and reinforced low fills on a loose sand subgrade, with particular emphasis on the behaviour of the fills after surface maintenance. Different types of geosynthetics (12 geogrids and a woven geotextile) were tested in a large equipment where the fills were subjected to cyclic loading. The results obtained showed that the presence of the reinforcement improved the performance of the fill during the first and second (after surface maintenance) loading stages. The gain in performance depended on the reinforcement type and characteristics. Optimum ranges for the ratio between geogrid aperture dimension and fill particle diameter were identified for which less fill particle breakage and greater load spreading angles were obtained. The results show that the specification of a geogrid reinforcement for applications such as in unpaved roads or railway tracks based on its tensile stiffness is necessary but not sufficient to obtain maximum efficiency from the reinforcement.
\end{abstract}

Keywords Geosynthetics $\cdot$ Reinforcement $\cdot$ Geogrids low fills - Compressible subgrade - Surface maintenance . Unpaved roads

Ennio M. Palmeira

palmeira@unb.br

Ivonne A. M. G. Góngora

ivonnnegg_86@yahoo.com

1 Department of Civil and Environmental Engineering, Faculty of Technology, University of Brasília, Brasília, DF 70.910-900, Brazil

\section{List of symbols}

$a_{\mathrm{eq}} \quad$ Equivalent geogrid aperture dimension $\left[=\left(a_{\mathrm{M}} \cdot a_{\mathrm{CM}}\right)^{1 / 2}\right](\mathrm{mm})$

$a_{\mathrm{CM}}$ Geogrid aperture width along the cross machine direction $(\mathrm{mm})$

$a_{\mathrm{M}} \quad$ Geogrid aperture width along the machine direction $(\mathrm{mm})$

ASM Geogrid aperture stability modulus (N-m/degree)

$B \quad$ Diameter of the loading plate $(\mathrm{mm})$

$B_{\mathrm{g}} \quad$ Percentage by weight of broken gravel particles (dimensionless)

$D_{n} \quad$ Particle diameter for which $n \%$ in mass of the remaining particles are smaller than that diameter (mm)

$D_{\max } \quad$ Maximum fill particle diameter (mm)

$f_{\mathrm{a} / D} \quad$ Reduction factor for the influence of the ratio $a_{\mathrm{eq}} /$ $D_{\max }$

GPF Geogrid property factor (dimensionless)

$J \quad$ Reinforcement tensile stiffness $(\mathrm{kN} / \mathrm{m})$

$J_{5 \%} \quad$ Reinforcement secant tensile stiffness at $5 \%$ strain $(\mathrm{kN} / \mathrm{m})$

$N \quad$ Number of load repetitions during cyclic loading (dimensionless)

$p \quad$ Pressure on the fill surface $(\mathrm{kPa})$

TBR Traffic benefit ratio (dimensionless)

$t_{\mathrm{M}} \quad$ Average thickness of the grid members parallel to the machine direction $(\mathrm{mm})$

$t_{\mathrm{CM}} \quad$ Average thickness of the grid members parallel to the cross-machine direction $(\mathrm{mm})$

$T_{\max } \quad$ Reinforcement tensile strength $(\mathrm{kN} / \mathrm{m})$

$\alpha_{\mathrm{b}} \quad$ Fraction of grid members' lateral area available for bearing in the grid aperture (dimensionless)

$\alpha_{\mathrm{s}} \quad$ Fraction of grid area which is solid in plan (dimensionless) 
$\Delta W_{k f} \quad$ Final fraction of the sample weight corresponding to a given range of gravel particles after breakage

$\Delta W_{k i} \quad$ Initial fraction of the sample weight corresponding to a given range of gravel particles sizes before breakage

$\varepsilon_{\max } \quad$ Maximum reinforcement strain (\%)

$\theta \quad$ Load spreading angle $\left(^{\circ}\right)$

$\xi \quad$ Correction factor for the influence of the reinforcement on soil properties (dimensionless)

\section{Introduction}

Geosynthetics have been extensively used as reinforcement in different geotechnical engineering works, such as embankments on soft soils, steep slopes and retaining structures, pavements and unpaved roads. For the latter, significant benefits can be brought about by the use of geosynthetic to reinforce roads on weak subgrades. The presence of the reinforcement reduces lateral spreading of the fill material, reduces the stresses transmitted to the subgrade and, in case large deformations of the system are allowed, the reinforcement membrane effect improves even further the performance of the road. The practical consequences are the reduction of fill material consumption, reduction of road deformation, increased road life and less maintenance requirement. The reduction of maintenance is an important contribution from the reinforcement that is usually neglected in the design of such works and in the cost-effectiveness analysis of the solution [1].

The use of geosynthetic to reinforce low fill layers on weak subgrades, such as in unpaved roads, railways or shallow foundations, has been investigated by many researchers in the last decades [2-8]. In the 70s and early 80s geotextiles (woven and nonwoven) were used as reinforcement $[2,3]$ and they combined the functions of reinforcement, separation and drainage. Geogrids started to gain ground with respect to geotextiles in such applications because of their greater interaction with granular fill materials and larger values of tensile stiffness.

Several numerical studies [9-13, for instance] have contributed to a better understanding of the influence of geosynthetic reinforcement on performance of low fills on weak subgrades. In the case of unpaved roads, design methods have also been proposed by several researchers throughout the last 4 decades [14-18]. Despite the importance and relevance of these contributions, an accurate prediction of the behaviour of low fill layers, either reinforced or not, on weak ground is still a challenge because of the complex nature of such works. These complexities are related to conditions such as cyclic loading and its influence on soil properties and mechanical behaviour, large deformations, interaction between soils and reinforcement, low strength and high compressibility of the subgrade, construction practices and control, etc. On the other hand, much lower deformations are allowed for other low fill applications as bearing layers, such as in railways and shallow foundations. However, soil-geosynthetic interaction remains as a complex and extremely important phenomenon in such cases as well.

The influence of the presence of reinforcement on the reduction of maintenance services in low fills (unpaved roads and railway tracks, for instance) has been very little investigated. Palmeira and Cunha [19] and Palmeira and Ferreira [20] carried out model tests on reinforced and unreinforced unpaved roads subjected to surface maintenance after a target rut depth had been reached. The results showed that after maintenance the presence of the reinforcement continued to improve road performance very significantly. Palmeira and Antunes [1] presented and discussed contributions brought by the reinforcement to the road performance after surface maintenance in large scale laboratory tests. These authors also showed that an initially more expensive geosynthetic, but being more efficient as reinforcement, can prove more economically attractive after a few road surface maintenance cycles. Palmeira [21] presented a limit equilibrium approach to estimate the gains in load capacities of reinforced and unreinforced roads after surface maintenance.

Most research on problems involving low reinforced fills has studied the behaviour of such works on soft saturated subgrades. However, the presence of the reinforcement can be also beneficial in the cases of fills on collapsible soils and on subgrades consisting of loose sands. Although soil improvement techniques or geocells can be employed in these situations, these solutions are usually significantly more expensive or time consuming than the use of a geosynthetic reinforcement layer at the base of the fill. This paper investigates some physical, mechanical and interaction properties of geosynthetic reinforcement on the behaviour of low fills built on loose subgrades and subjected to surface maintenance. The authors believe the study is particularly relevant to unpaved roads, but some results and conclusions obtained may be extended to some extent to other low reinforced fill applications such as in paved roads and railways, for instance. The experimental methodology adopted, results and discussions are presented in the following items.

\section{Experiments}

\section{Equipment}

The apparatus used in the experiments consisted of a rigid tank $1200 \mathrm{~mm}$ in diameter and $520 \mathrm{~mm}$ high, as shown in 
Fig. 1 [22]. A $300 \mathrm{~mm}$ thick gravel fill simulated a bearing layer on a compressible subgrade consisting of a $220 \mathrm{~mm}$ thick loose sand layer. It is acknowledged that under field conditions in unpaved roads, for instance, much thicker subgrade layers would occur. However, the main objective of the study was to identify and quantify the influence of soilreinforcement interaction parameters and of relevant reinforcement properties on fill performance. So, the use of a smaller thickness was intended to allow a faster test preparation and testing of a significant number of reinforcement materials, but still resembling practical situations such as those found in unpaved roads and railway tracks on compressible ground. Although the results obtained might be somewhat different had a thicker subgrade been used, unreinforced and reinforced test results were obtained under the same subgrade conditions and the authors believe that in comparative terms the conclusions obtained are valid. Similar subgrade types (sand) and/or thicknesses were also employed in large scale tests carried out by Cancelli et al. [23], Brown et al. [24] and Hussaini [25], for instance.

The cyclic vertical load was applied to the fill surface by a $200 \mathrm{~mm}$ diameter steel plate with a frequency of $1 \mathrm{~Hz}$. The load was provided by a jack connected to a hydraulic system so that a vertical stress of $560 \mathrm{kPa}$ was applied to the fill surface. Load on the plate and its vertical displacements were measured by a load cell and displacement transducers, respectively. Displacement transducers were also installed along the surface of the fill to allow the measurement of fill surface profile during the test. The signals from the instrumentation were acquired and processed by a Lynx ADS 2000 data logger and a microcomputer.

The maintenance of the fill surface was carried out when a loading plate vertical displacement of $75 \mathrm{~mm}$ was reached and consisted of filling the rut with the same fill material and under the same initial conditions. After rut repair the test was restarted for a new loading phase.

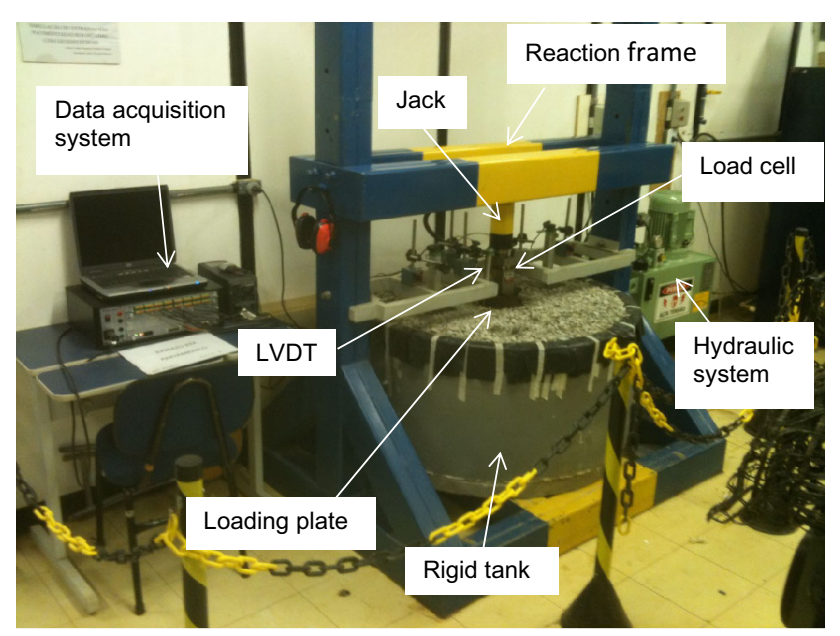

Fig. 1 View of the equipment used during one of the tests [22]

\section{Materials}

The fill consisted of a $300 \mathrm{~mm}$ thick gravel layer with particle diameters ranging from 1.5 to $21 \mathrm{~mm}$, with an average particle diameter $\left(D_{50}\right)$ of $10.5 \mathrm{~mm}$ and a coefficient of uniformity (CU) equal to 7.7. The fill was compacted (static compaction) to a dense state in three layers, $100 \mathrm{~mm}$ each, to achieve a relative density of $83 \%$. Under such conditions, the gravel friction angle obtained in a medium size $(300 \mathrm{~mm} \times 300 \mathrm{~mm} \times 200 \mathrm{~mm}$ specimens $)$ direct shear test equipment was equal to $43^{\circ}$. Table 1 presents additional information on the geotechnical properties of the fill material.

A clean uniform sand with particle diameters varying between 0.2 and $2.0 \mathrm{~mm}$ was used to prepare the subgrade layer. The average particle diameter of the sand was equal to $1.01 \mathrm{~mm}$ and its coefficient of uniformity was equal to 2.6. The subgrade layer was prepared using the sand rain technique with particles falling from height of $100 \mathrm{~mm}$, which yielded a relative density of $30 \%$. For such relative density the sand friction angle obtained in direct shear tests was equal to $31^{\circ}$ and the California bearing ratio (CBR) was equal to $1.6 \%$. Table 1 also presents additional information on the sand used in the subgrade.

\section{Geosynthetics}

Twelve geogrids and a woven geotextile were used as reinforcement. Table 2 presents the main properties of the reinforcements. In all test the reinforcement layer was installed at the fill-subgrade interface. The tensile stiffness of the geogrids tested varied between 72 and $1165 \mathrm{kN} / \mathrm{m}$,

Table 1 Properties of the soils

\begin{tabular}{|c|c|c|}
\hline Property & Fill & Subgrade \\
\hline$D_{10}(\mathrm{~mm})^{\mathrm{a}}$ & 1.49 & 0.46 \\
\hline$D_{50}(\mathrm{~mm})$ & 10.51 & 1.01 \\
\hline$D_{85}(\mathrm{~mm})$ & 16.0 & 1.63 \\
\hline Coefficient of uniformity $\left(D_{60} / D_{10}\right)$ & 7.7 & 2.6 \\
\hline Unit weight $\left(\mathrm{kN} / \mathrm{m}^{3}\right)$ & 17.3 & 16.7 \\
\hline Specific gravity of soil solids & 2.65 & 2.69 \\
\hline Relative density (\%) & 83 & 30 \\
\hline Cohesion $(\mathrm{kPa})^{\mathrm{b}}$ & 0 & 0 \\
\hline Friction angle (degrees) ${ }^{b}$ & 43 & 31 \\
\hline California bearing ratio $(\%)$ & NA & 1.6 \\
\hline Los Angeles abrasion (\%) & 34 & $\mathrm{NA}^{\mathrm{c}}$ \\
\hline \multicolumn{3}{|c|}{$\begin{array}{l}D_{n}=\text { soil particle diameter for which } n \% \text { in mass of the remaining } \\
\text { particles are smaller than that diameter }\end{array}$} \\
\hline
\end{tabular}


as per the ASTM D6637 test method. Note that geogrids G1 and G4 are uniaxial products, whereas the others are biaxial ones. Although similar to squares in shape in most cases, the dimensions of the apertures of the geogrids tested were measured and the values of equivalent aperture $\left(a_{\mathrm{eq}}\right)$, defined as the geometric mean of the dimensions of the aperture [24], are presented in Table 2. The equivalent aperture dimension of the geogrids varied between 12.8 and $32.8 \mathrm{~mm}$. The values of geogrid aperture stability modulus (ASM, as per Kinney and Xiaolin [26]) are also presented in that table. Geogrids G1, G2 and G4 were manufactured with polyester fibers, whereas the others were made with polypropylene fibers. Geogrids G1 to G6 are commercially available products, whereas geogrids $\mathrm{G} 7$ to G12 were assembled in the laboratory using polypropylene stripes. The latter were intended to allow variations of specific geogrid properties (aperture dimensions, for instance) while keeping other properties (tensile stiffness or ASM, for instance) constant. The woven geotextile was made with polyester fibers and presented a secant tensile stiffness at $5 \%$ strain $\left(J_{5 \%}\right)$ equal to $1022 \mathrm{kN} / \mathrm{m}$, which is close to the tensile stiffness of the stiffest geogrid tested (G1, $\left.J_{5 \%}=1165 \mathrm{kN} / \mathrm{m}\right)$. Additional information on materials and testing methodology can be found in Góngora [22] and in a companion paper by Palmeira and Góngora [27].

\section{Results}

\section{Load-Displacement Behaviour}

Figure 2 shows results for unreinforced and reinforced fills in terms of loading plate vertical displacement versus number of load repetition $(N)$ for the two loading stages considered (before and after surface maintenance) for the tests with the woven geotextile and geogrids G1 to G12. The results obtained during the first loading stage are shown in Fig. 2a, b and are discussed in detail in Palmeira and Góngora [27]. The best performance in terms of number of load repetitions for the target $75 \mathrm{~mm}$ plate vertical displacement to be reached was obtained for the fills reinforced with grids G1, G2 and G4. The number of load repetitions varied between 3755 (for grid G7) and 340,068 (for grid G1). The value obtained for the unreinforced fill was considerably smaller $(N=2810)$. The value of $N$ for the test with the geotextile was equal to 11,437 , which is considerably larger than that for the unreinforced fill, although smaller than the values of $N$ obtained in the tests with geogrids G1, G2, G3 and G4.

The results of plate vertical displacement versus number of load repetitions for the second loading stage, after surface repair, are depicted in Fig. 2c, d. In this loading stage the fills reinforced with grids $\mathrm{G} 1, \mathrm{G} 2$ and $\mathrm{G} 4$ continued to

Table 2 Properties of the geosynthetics

\begin{tabular}{|c|c|c|c|c|c|c|c|c|c|c|}
\hline Reinf. & $T_{\max }^{\mathrm{a}}(\mathrm{kN} / \mathrm{m})$ & $\varepsilon_{\max }(\%)$ & $J_{5 \%}(\mathrm{kN} / \mathrm{m})$ & $\operatorname{ASM}\left(\mathrm{N}-\mathrm{m} /{ }^{\circ}\right)$ & $t_{\mathrm{M}} / t_{\mathrm{CM}}^{\mathrm{b}}(\mathrm{mm})$ & $a_{\mathrm{M}} / a_{\mathrm{CM}}^{\mathrm{b}}(\mathrm{mm})$ & $a_{\mathrm{eq}}$ & $\alpha_{\mathrm{s}}$ & $\alpha_{\mathrm{b}}$ & $\mathrm{TBR}^{\mathrm{c}}$ \\
\hline $\mathrm{G} 1^{\mathrm{d}}$ & $100 / 30^{\mathrm{b}}$ & 8.0 & $893 / 300^{\mathrm{b}}$ & 0.033 & $1.8 / 1.2$ & $18.4 / 21$ & 19.7 & 0.37 & 0.80 & 121.0 \\
\hline G2 & 80 & 13 & 811 & 0.074 & $2.0 / 1.0$ & $23 / 35$ & 28.4 & 0.32 & 0.83 & 78.7 \\
\hline G3 & 18 & 10 & 417 & 0.040 & $1.2 / 0.6$ & 15/11.6 & 13.2 & 0.37 & 0.83 & 6.5 \\
\hline $\mathrm{G} 4^{\mathrm{d}}$ & $110 / 30^{\mathrm{b}}$ & 12 & $1165 / 300^{\mathrm{b}}$ & 0.036 & $1.9 / 1.4$ & $18.5 / 14.1$ & 16.2 & 0.35 & 0.81 & 72.6 \\
\hline G5 & 38 & 10 & 474 & 0.107 & $1.6 / 1.0$ & $26 / 40$ & 32.2 & 0.31 & 0.83 & 2.9 \\
\hline G6 & 43 & 8 & 474 & 0.029 & $1.3 / 0.8$ & $11 / 15$ & 12.8 & 0.35 & 0.81 & 4.0 \\
\hline G7 & 15 & 14 & 72 & 0.043 & $0.4 / 0.4$ & $30 / 30$ & 30.0 & 0.65 & 0.59 & 1.3 \\
\hline G8 & 15 & 14 & 117 & 0.067 & $0.6 / 0.6$ & $30 / 30$ & 30.0 & 0.65 & 0.59 & 1.3 \\
\hline G9 & 15 & 14 & 164 & 0.095 & $1.0 / 1.0$ & $60 / 60$ & 60.0 & 0.45 & 0.74 & 2.1 \\
\hline G10 & 15 & 14 & 300 & 0.103 & $1.2 / 1.2$ & $60 / 60$ & 60.0 & 0.45 & 0.74 & 2.3 \\
\hline G11 & 21 & 12 & 416 & 0.133 & $1.0 / 1.0$ & $30 / 30$ & 30.0 & 0.56 & 0.67 & 1.7 \\
\hline G12 & 11.5 & 12 & 261 & 0.054 & $1.0 / 1.0$ & $60 / 60$ & 60.0 & 0.36 & 0.80 & 1.4 \\
\hline $\mathrm{GT}^{\mathrm{e}}$ & $103 / 50^{\mathrm{b}}$ & 10 & 1022 & NA & 0.5 & NA & NA & 1.00 & NA & 4.1 \\
\hline
\end{tabular}

$T_{\max }$, tensile strength; $\varepsilon_{\max }$, maximum tensile strain, $J_{5 \%}$, secant tensile stiffness at $5 \%$ tensile strain; ASM, aperture stability modulus (or torsional rigidity); $t_{\mathrm{M}}$, average thickness of the grid members parallel to the machine direction; $t_{\mathrm{CM}}$, average thickness of the grid members parallel to the cross-machine direction; $a_{\mathrm{M}}$, average aperture width along the machine direction; $a_{\mathrm{CM}}$, average aperture width along the crossmachine direction, $a_{\mathrm{eq}}$, equivalent aperture dimension $\left[=\left(a_{\mathrm{M}} \cdot a_{\mathrm{CM}}\right)^{1 / 2}\right] ; \alpha_{s}$, fraction of the grid area in plan which is solid; $\alpha_{\mathrm{b}}$, fraction of the aperture area available for bearing; TBR, traffic benefit ratio for the 1st loading stage (before surface maintenance); NA, not applicable

${ }^{a}$ Geogrid tensile properties obtained as per ASTM D6637

${ }^{b}$ Figure on the left is the property value along machine direction and on the right along cross-machine direction

c First loading stage, before surface repair

d Uniaxial grids

e Woven geotextile (code GT) 


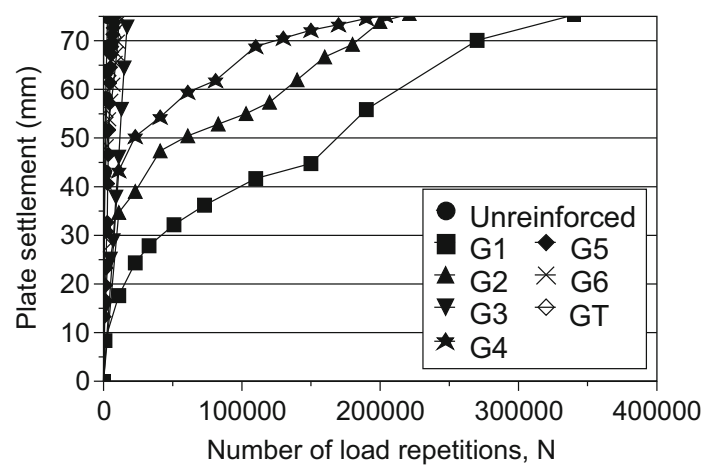

(a)

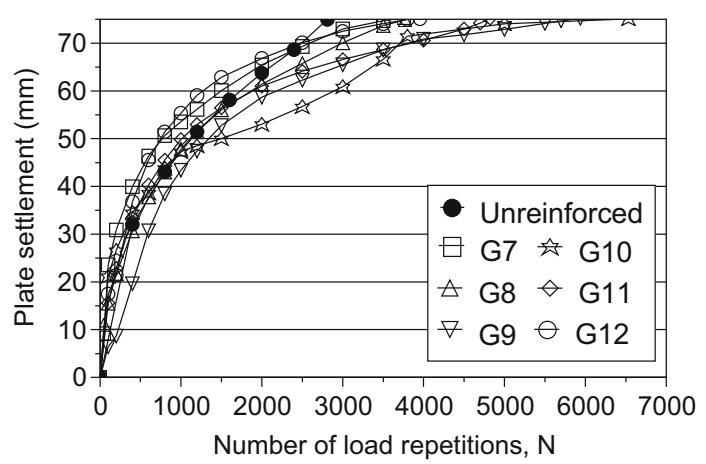

(b)

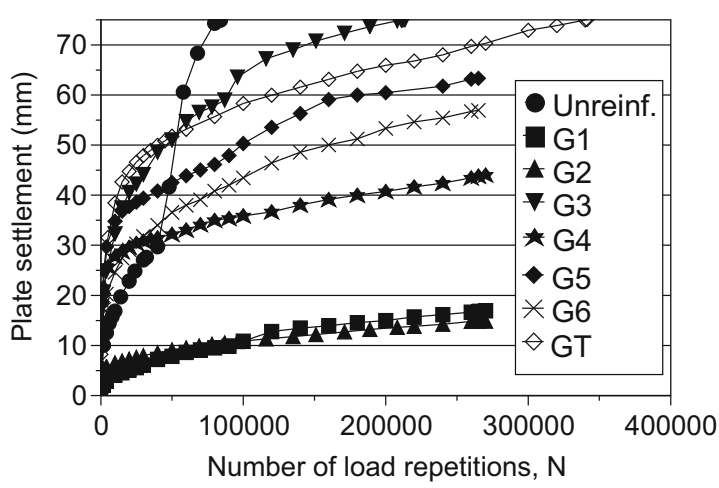

(c)

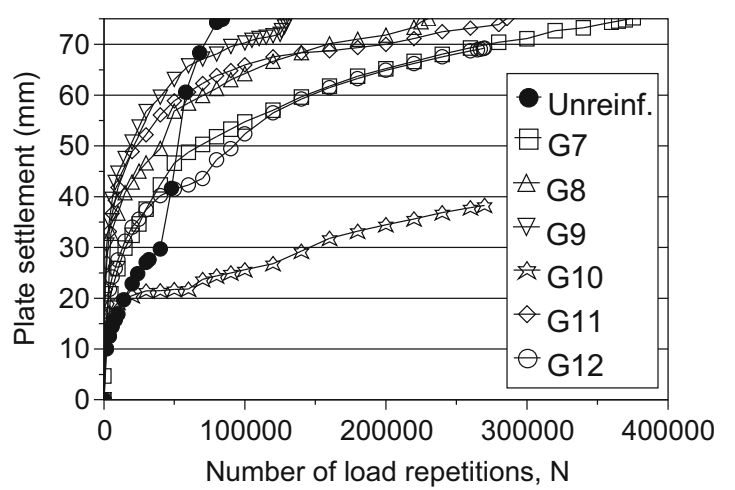

(d)
4Fig. 2 Plate settlement versus number of load repetitions. a 1st loading stage-geogrids G1 to G6 and GT (Palmeira and Góngora [27]). b 1st loading stage-geogrids G7 to G12 (Palmeira and Góngora [27]). c 2nd loading stage, after surface repair-geogrids G1 to G6 and GT. d 2nd loading stage, after surface repair-geogrids G7 to $\mathrm{G} 12$

present the best performance and their tests together with the tests with grids G5, G6 and G10 were interrupted at $N=270,000$. This was done because of the expected long duration of these tests until the target plate vertical displacement could be reached. In the second loading stage a value of $N$ equal to 84,042 was obtained for the unreinforced fill, which is considerably larger than that obtained in the first loading stage. One of the reasons for larger values of $N$ in unreinforced and reinforced fills in the second loading stage was the compaction of the subgrade soil during the first loading stage. In addition, reinforcement membrane effect must have also played an important role due to larger settlements at the fill-subgrade interface. It should also be noted that during the earlier part of the second loading stage the unreinforced fill presented a stiffer response in terms of vertical displacement versus $N$ in comparison with the reinforced ones. This behaviour can be attributed to more intense compaction of the subgrade soil in the unreinforced test, because the stresses transferred to that layer in the reinforced tests were considerably smaller than those in the unreinforced test [22, 27]. In addition, after the end of the first loading stage and before the start of the second loading stage the tensioned geogrid reinforcement probably pushed fill particles upwards due to the reduction of its tensile loads under unloaded conditions, which is likely to have loosened the fill layer to some extent. The breakage of fill particles may have also influenced the results of vertical displacements in the beginning of the 2nd loading stage. The intensity of fill particle breakage was only assessed at the end of the 2nd loading stage, as will be discussed later in this paper.

A sharp increase in the plate displacement for a value of $N$ of approximately 40,000 can be noted in Fig. 2c in the unreinforced fill test. This behavior was a consequence of more intense fill particle breakage in the unreinforced fill, as will be discussed later in this paper.

Geogrids G7 to G12, assembled in the laboratory, were less effective in reinforcing the fill than G1 to G6. For the former case, the values of $N$ at the end of the first loading stage varied between 3755 (for grid G7) and 6532 (for grid G10), as shown in Fig. 2b. Regarding the second loading stage (Fig. 2d), the values of $N$ in tests with geogrids G7 to G12 varied between 129,300 (for grid G9) and 270,000 (for 
grid G10). For tests with these grids the best performance was obtained in the road reinforced with geogrid G10, whose test was interrupted at $N=270,000$, at a plate vertical displacement of $38.3 \mathrm{~mm}$, approximately half the target value (Fig. 2d).

Figure 3a-d show the profiles of vertical displacements along the fill surface for tests with geogrids G1 to G12 and geotextile GT for both loading stages for the number of load repetitions obtained at the end of the first and second loading stages of the unreinforced test $(N=2810$ and 84,042 , respectively). Negligible vertical displacements can be noted for values of distance $(x)$ from the loading plate center normalized by the plate diameter $(d)$ greater than 1. Less vertical displacements can be observed in the tests with geogrids G1 to G6 in comparison with those in the unreinforced test in both loading stages (Fig. 3a, c). For the tests with geogrids G7 to G12 greater differences among fill surface profiles can be noted depending on the geogrid considered (Fig. 3d), in comparison with the results obtained in the first loading stage (Fig. 3b).

\section{Traffic Benefit Ratio}

The traffic benefit ratio (TBR) provides a measure of the benefit of the presence of the reinforcement with respect to the increase in the number of load repetitions supported by the fill for a given rut depth. TBR is defined as the number of load repetitions for a given vertical displacement at the reinforced fill surface divided by the number of load repetitions for the same vertical displacement in the unreinforced fill. Because the final loading plate settlement value was not reached in some reinforced tests during the second loading stage, the expected values of $N$ for a settlement of $75 \mathrm{~mm}$ in these tests were estimated by extrapolation. In all tests interrupted before the final settlement a linear trend of variation of plate settlement with $N$ was observed at the later stages of the test, with values of $R^{2}$ obtained in the linear regression fitting process greater than 0.985 (greater than 0.990 in most cases). It is acknowledged that this procedure may be subject to criticism. It is not necessarily true that linear trend would persist had the test been carried out until the final plate settlement of $75 \mathrm{~mm}$ was reached, because breakage of particles or fatigue of materials might increase plate settlement development. However, the results in Fig. 2 show that the linear trends of variation of settlement with $N$ in the later stages of the tests persisted until the final settlement was reached in most cases. Bearing in mind the aforementioned limitations, the procedure adopted in extrapolating test results allowed comparisons between different reinforcements under similar conditions.

Figure 4 shows the values of TBR for each fill tested for both the first and the second loading stages. It can be noted

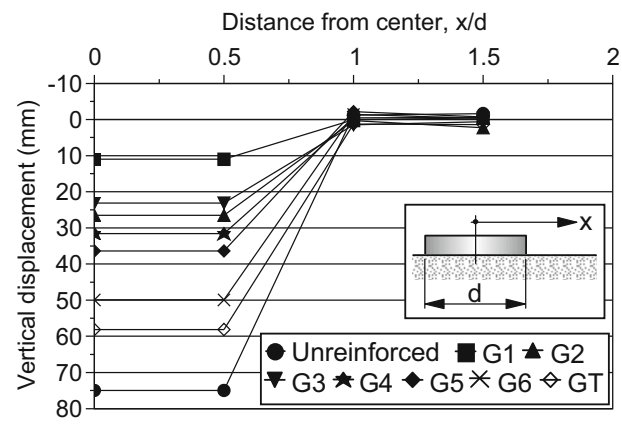

(a)

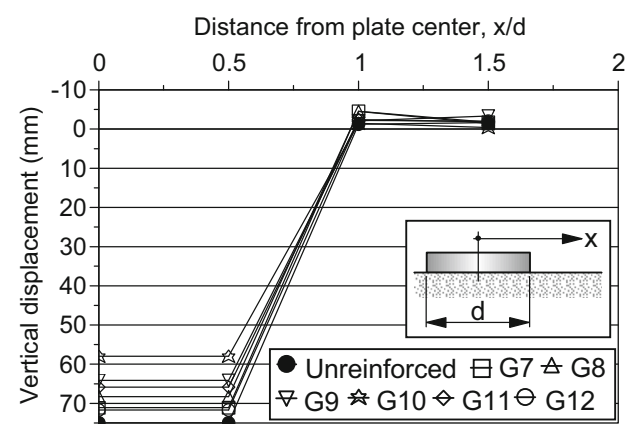

(b)

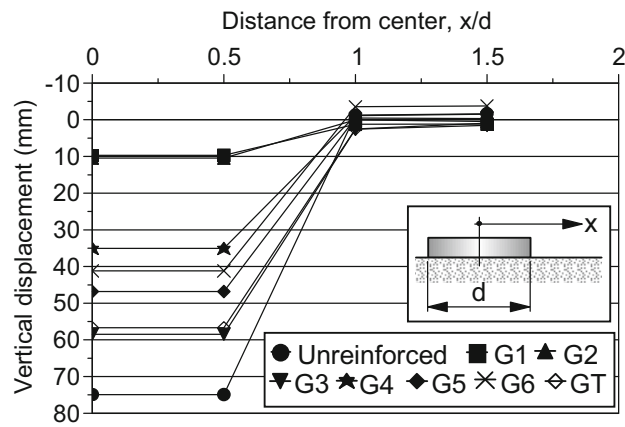

(c)

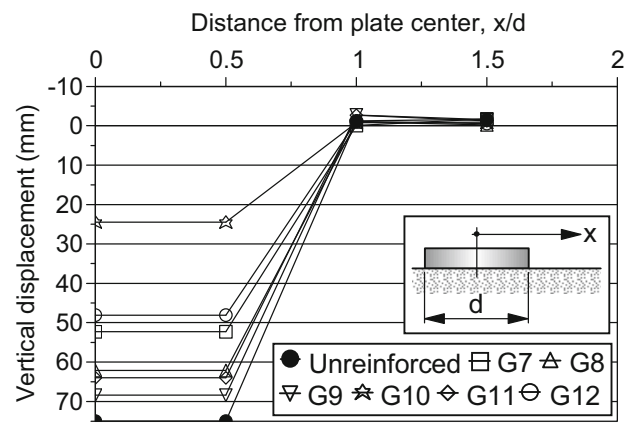

(d)

Fig. 3 Surface settlement profiles. a 1st loading stage—geogrids G1 to G6 and GT, $N=2810$ (Palmeira and Góngora [27]). b 1st loading stage—geogrids G7 to G12, $N=2810$ (Palmeira and Góngora [27]). c 2nd loading stage, after surface repair-geogrids G1 to G6 and GT, $N=84,042$. d 2nd loading stage, after surface repair-geogrids G7 to $\mathrm{G} 12, N=84,042$ 


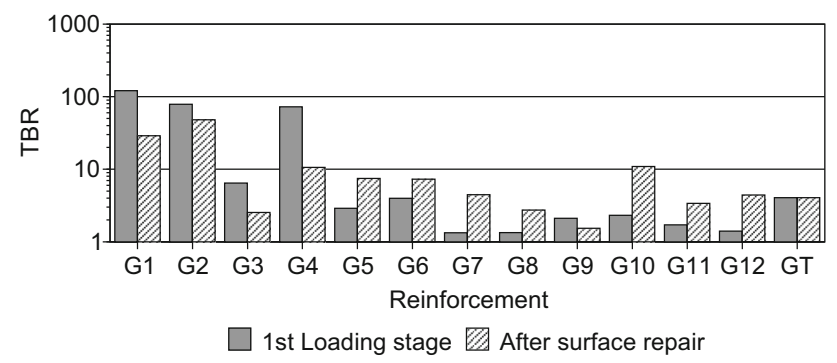

Fig. 4 Traffic benefit ratio (TBR) for each fill tested

that the best performances in both stages were obtained by the roads reinforced with geogrids G1 and G2. It can be noticed that in several cases the value of TBR was greater in the second loading stage, which was a consequence of the compaction of the subgrade soil during the first loading stage. Values of TBR between 1.34 (for grid G7) and 121 (for grid G1) were obtained in the first loading stage, whereas TBR values in the range 1.54 (grid G9) to 48.1 (grid G2) can be noted in the second loading stage. The values of TBR obtained for the fill reinforced with the woven geotextile (GT) in the first and second loading stages were approximately equal to 4 . Similar large or even larger values of TBR for fills on granular subgrades have also been found by Cancelli et al. [23] and even for fills on fine grained subgrades [28-30]. The results in Fig. 4 show that the presence of the reinforcement consistently improves road performance both under the first loading stage and after surface maintenance, corroborating the results obtained in other works $[1,19,21]$ regarding unpaved roads on fine grained subgrades.

The variation of TBR with geogrid secant tensile stiffness at $5 \%$ strain $\left(J_{5 \%}\right)$ is presented in Fig. 5a for the first loading stage [27] and in Fig. 5b for the second loading stage. A clear trend of TBR increase with $J_{5 \%}$ can be noted in both loading stages, with less scatter for the first one. That is not the case when the values of TBR are plotted against the geogrid ASM, as shown in Fig. 6a, b. In this case no clear trend can be observed, suggesting that for the test conditions ASM was not a relevant geogrid property with regard to fill performance. Poor or zero correlation between fill performance and ASM was also observed by other researchers [8, 31-34].

\section{Influence of Reinforcement Properties}

It is very difficult to accept that the performance of a reinforced road in terms of TBR can be expressed as a function of a single reinforcement property, such as $J_{5 \%}$, despite its importance. Other grid properties or parameters such as geometrical characteristics and soil-grid interaction parameters certainly play important roles. Palmeira and

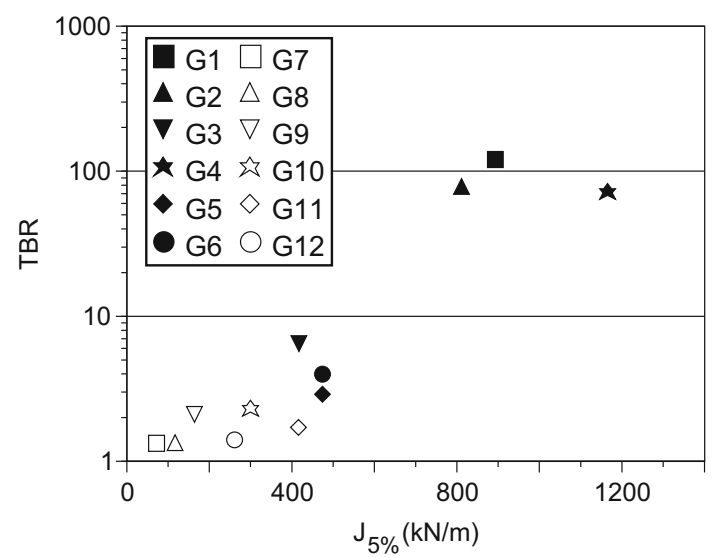

(a)

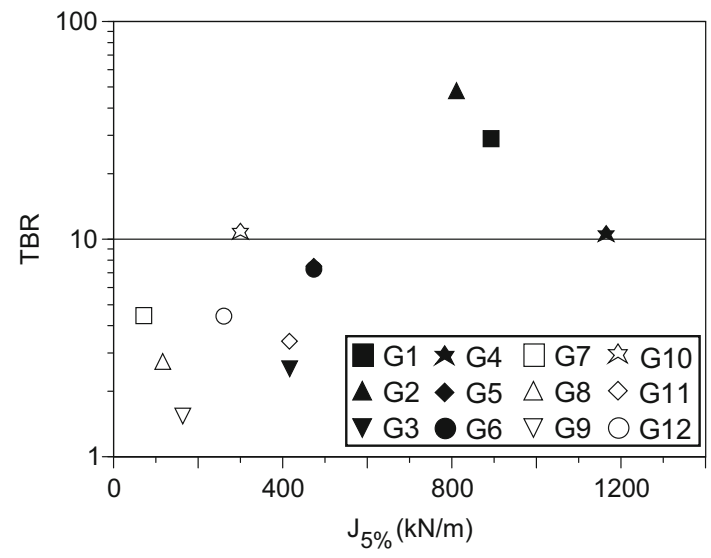

(b)

Fig. 5 TBR versus geogrid tensile stiffness. a 1st loading stage (Palmeira and Góngora [27]). b 2nd loading stage, after surface repair

Góngora [27] found good correlation between TBR values and a geogrid dimensionless property factor (GPF) for the first loading stage of the tests reported in this paper. The geogrid property factor was defined as:

$\mathrm{GPF}=\frac{J_{5 \%}}{p B} \cdot \alpha_{b} \cdot \frac{t_{\mathrm{GG}}}{D_{50}} \cdot f_{\mathrm{a} / D} \cdot \xi$

where $J_{5 \%}$ is the geogrid secant tensile stiffness at $5 \%$ tensile strain, $p$ is the vertical stress on the fill surface, $B$ is the diameter of the loaded area on the fill surface, $\alpha_{b}$ is the fraction of the total lateral area of the geogrid members available for bearing (passive resistance), $t_{\mathrm{GG}}$ is the geogrid thickness, $D_{50}$ is the average diameter of the fill material particles, $f_{a / D}$ is a correction factor to account for the influence of the ratio between fill particles diameter and geogrid aperture dimensions and $\xi$ is a correction factor to account for the influence of the reinforcement presence on soil properties. Further information and details on the components of Eq. 1 can be found in Palmeira and Góngora [27].

Figure 7 shows the correlation between TBR and GPF for $\xi$ equal to 1 (no influence of the reinforcement on the 


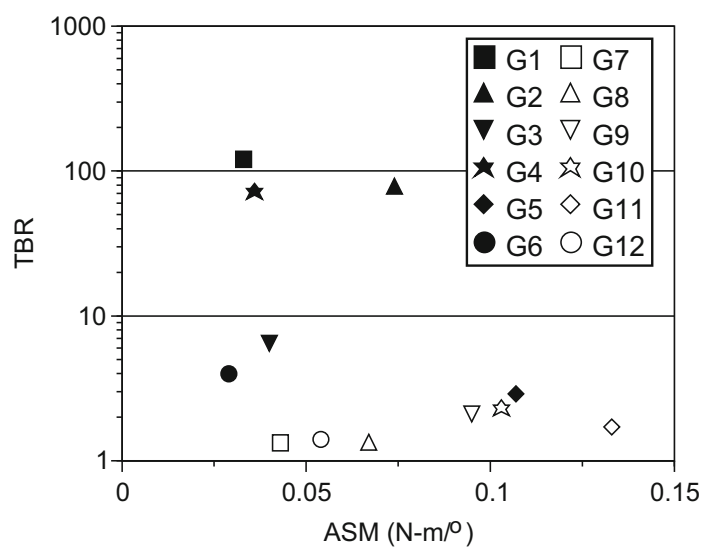

(a)

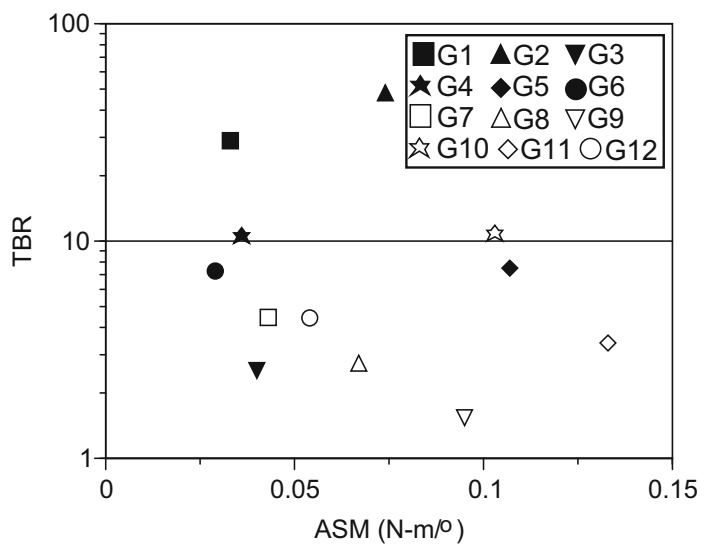

(b)

Fig. 6 TBR versus geogrid ASM. a 1st loading stage (Palmeira and Góngora [27]). b 2nd loading stage, after surface repair

surrounding soils properties). Although the general trend is TBR increasing with GPF, a large scatter of results can be noted in the second loading stage in comparison with the range of variation of TBR with GPF obtained by Palmeira and Góngora [27] for the first loading stage, which is also shown in Fig. 7 for comparison. This large scatter may be a consequence of the materials being submitted to much higher strains in the second loading stage, whose influences are not entirely captured by the definition of GPF. For instance, it would be expected that under larger strains the grid members might be bent or twisted, yielding to other soil-grid interaction mechanisms not present (at least at the same intensity) during the first loading stage. Increasing breakage of fill particles may also influence the accuracy of the proposed correlation.

\section{Breakage of Fill Particles}

The development of rut depth at a fill surface can be accelerated because of fill particle breakage. In this work samples of fill material were collected from two locations

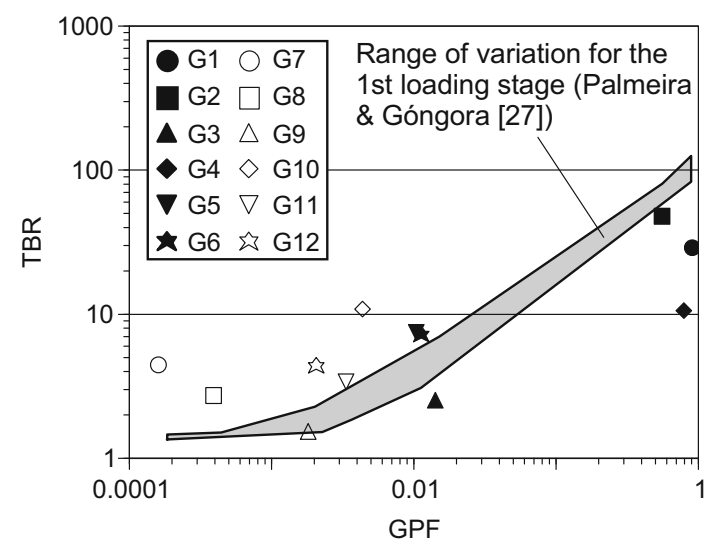

Fig. 7 TBR versus GPF-2nd loading stage

along the fill height after the end of the tests. The locations were at the fill top, just below the loading plate, and at the fill-subgrade interface or fill-reinforcement interface. The intensity of particle breakage can be quantified as per Marsal [35], as the percentage by weight of particles that have undergone breakage, given by:

$B_{g}=\sum_{1}^{n}\left(\Delta W_{k i}-\Delta W_{k f}\right) \quad$ for values of $\Delta W_{k i}-\Delta W_{k f}>0$

where $B_{\mathrm{g}}$ is the percentage by weight of the fill particles that have undergone breakage, $\Delta W_{k i}$ is the initial fraction of the sample weight corresponding to a given range of fill particle dimensions before breakage, $\Delta W_{k f}$ is final fraction of the sample weight corresponding to a given range of fill particles after breakage and $n$ is the number of ranges of particle dimensions for which $\Delta W_{k i}-\Delta W_{k f}>0$.

Figure 8 shows the values of $B_{\mathrm{g}}$ obtained at the top and bottom of the fill layer in all tests performed. In general, the breakage of fill particles was more intense at the base of the fill, but marginally larger than at the top in most reinforced tests. It can be noted that particle breakage was significantly greater in the unreinforced test in comparison with the reinforced ones. The roads reinforced with geogrids $\mathrm{G} 1, \mathrm{G} 2$, G4 and G7 were the ones with least particle breakage. Particle breakage in the fill reinforced with the woven geotextile was greater than in most geogrid reinforced fills, but still significantly less than that in the unreinforced fill.

The variation of $B_{\mathrm{g}}$ with geogrid tensile stiffness is depicted in Fig. 9. Despite the significant scatter, the results suggest some trend of reduction of $B_{\mathrm{g}}$ with the increase of $J_{5 \%}$. However, the tensile stiffness is certainly not the only geogrid parameter influencing particle breakage in this type of problem, as suggested by the scatter of results in the $80-500 \mathrm{kN} / \mathrm{m}$ range of $J_{5 \%}$ in Fig. 9 .

Figure 10 presents the variation of $B_{\mathrm{g}}$ with the ratio between the equivalent geogrid aperture dimension $\left(a_{\mathrm{eq}}\right)$ and 


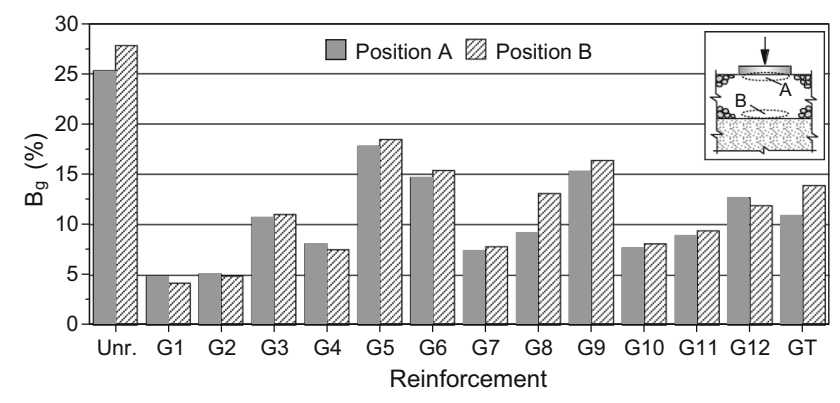

Fig. 8 Percentage of fill broken particles in each test

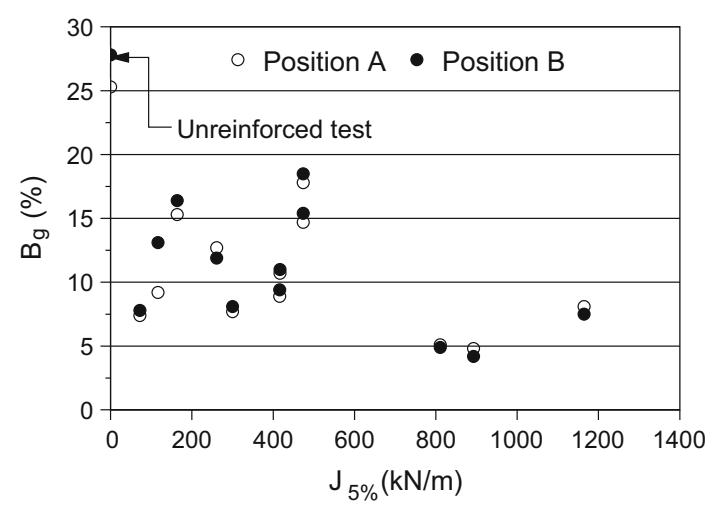

Fig. 9 Percentage of fill broken particles versus geogrid tensile stiffness

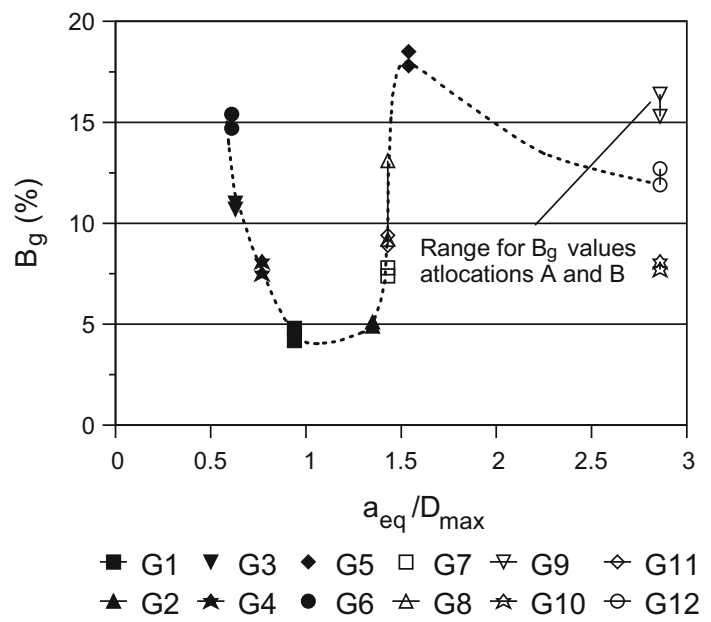

Fig. 10 Percentage of broken particles versus normalised equivalent geogrid aperture dimension

fill material maximum particle diameter $\left(D_{\max }\right)$. The results in this figure show that less breakage took place for values of $a_{\mathrm{eq}} / D_{\max }$ between 0.7 and 1.35. Palmeira and Góngora [27] observed that geogrids with $a_{\mathrm{eq}} / D_{\max }$ in this range performed best regarding TBR values for the first loading stage. This was also the case for the second loading stage, as shown in Fig. 11, where the variation of TBR with $a_{\mathrm{eq}} / D_{\mathrm{max}}$ is plotted

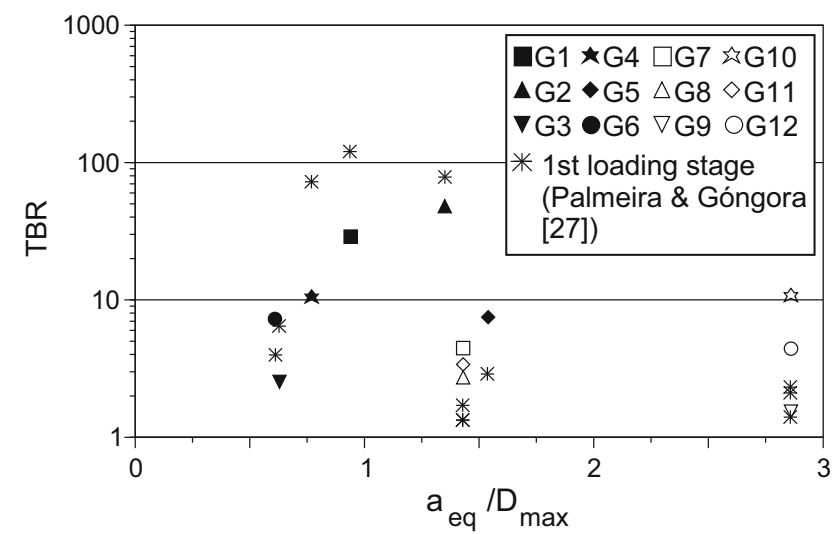

Fig. 11 TBR versus normalised equivalent geogrid aperture dimension

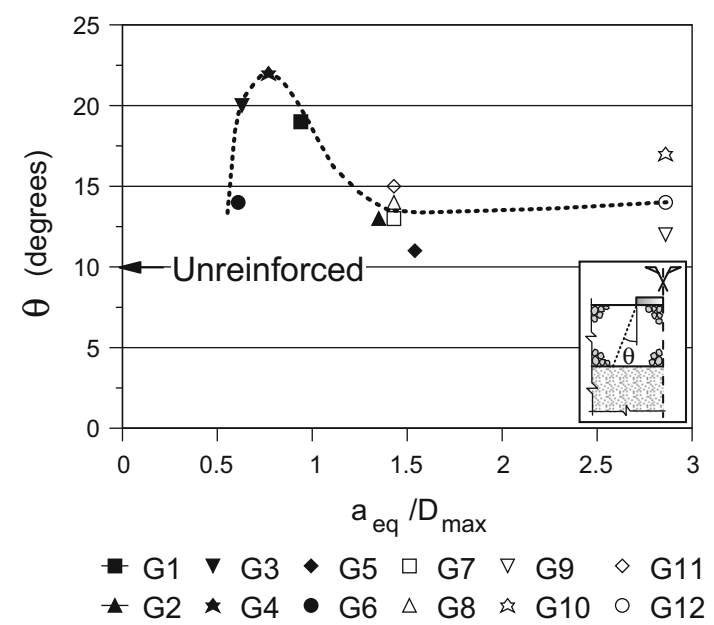

Fig. 12 Load spreading angle versus normalised equivalent aperture dimension

for the first (Palmeira and Góngora [27]) and second loading stages. Despite the greater scatter in the results for the second loading stage, the optimum range of $a_{\mathrm{eq}} / D_{\mathrm{max}}$ in terms of largest values of TBR is similar to the one obtained in the first loading stage. The results in Fig. 10 seem to indicate another benefit in choosing the most efficient relation between fill particles and grid aperture dimensions, which is less particle breakage. This reduced breakage may be associated with a better interlock between particles and grid apertures, which reduces the mobility of the particles and consequently their degradation by abrasion and breakage. Roughness of the grid members is also likely to influence the breakage level to an unknown extent.

\section{Load Spreading Angles}

After the end of the tests careful excavation of the fill material allowed the estimate of the load spreading angles in 


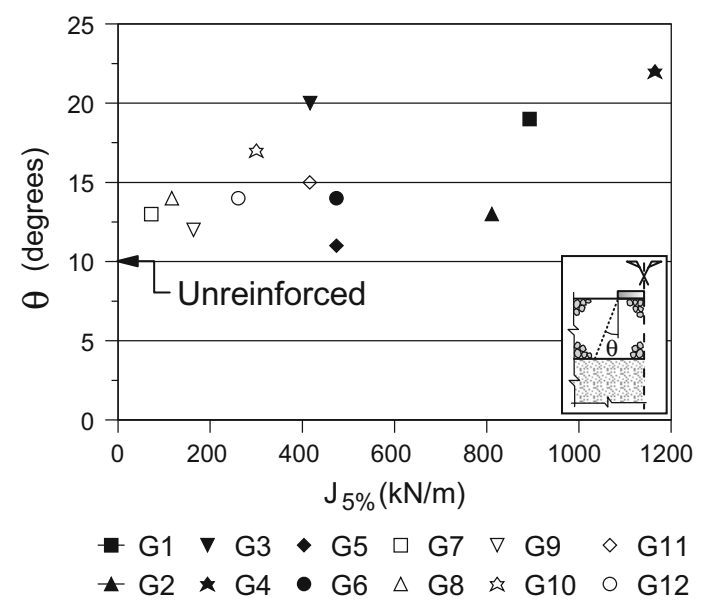

(a)

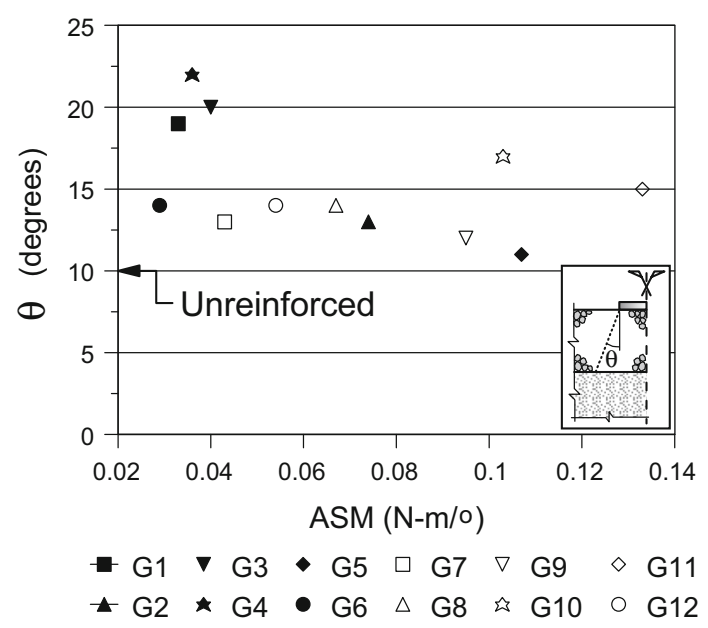

(b)

Fig. 13 Load spreading angle versus geogrid mechanical properties. a $\theta$ versus $J_{5 \%}$. b $\theta$ versus ASM

each test based on the position of the loading plate edge and the deformed shape of the fill-subgrade interface. Table 3 presents the values of the spreading angle $(\theta)$ obtained in each test. The values obtained in reinforced tests varied between $11^{\circ}$ and $22^{\circ}$ and were consistently greater than the value obtained in the unreinforced test $\left(10^{\circ}\right)$. The largest values of $\theta$ where obtained in the tests with geogrids $\mathrm{G} 1$ $\left(19^{\circ}\right), \mathrm{G} 3\left(20^{\circ}\right)$ and $\mathrm{G} 4\left(22^{\circ}\right)$. The value obtained for the geotextile reinforced road was equal to $14^{\circ}$. Larger values of $\theta$ have been reported in the literature in tests with different fill, reinforcement and subgrade materials [1, 19, 20].

Figure 12 shows the variation of load spreading angle with the equivalent grid aperture dimension normalized by the maximum fill particle diameter. It can be noted that the largest values of $\theta$ were obtained for $a_{\mathrm{eq}} / D_{\mathrm{max}}$ ranging from 0.7 to 1.0 , with the maximum $\theta$ being obtained for $a_{\mathrm{eq}} /$ $D_{\max } \cong 0.8$. The $a_{\mathrm{eq}} / D_{\max }$ range of 0.7 to 1.0 is close to that which the largest values of TBR in the 1st loading
Table 3 Load spreading angles in reinforced and unreinforced tests

\begin{tabular}{ll}
\hline Reinforcement & $\theta\left(^{\circ}\right)$ \\
\hline Unreinforced & 10 \\
G1 & 19 \\
G2 & 13 \\
G3 & 20 \\
G4 & 22 \\
G5 & 11 \\
G6 & 14 \\
G7 & 13 \\
G8 & 14 \\
G9 & 13 \\
G10 & 17 \\
G11 & 15 \\
G12 & 14 \\
GT & 14 \\
\hline$\theta=$ load spreading angle &
\end{tabular}

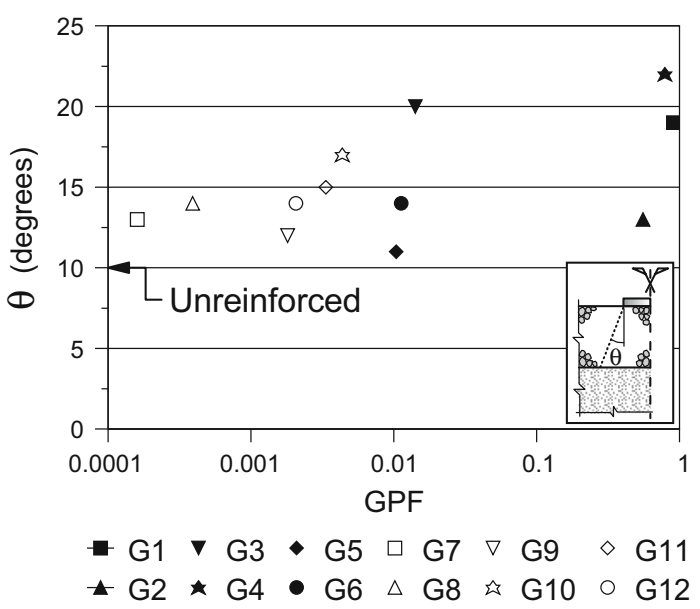

Fig. 14 Load spreading angle versus GPF

stage and lowest values of $B_{g}$ were obtained $\left(a_{\mathrm{eq}} / D_{\max }\right.$ in the $0.7-1.35$ range). These results suggest that an appropriate $a_{\mathrm{eq}} / D_{\max }$ ratio favouring good interaction between fill material and geogrid enhances the load spreading angle. This is likely to be a consequence of less movable fill particles in case of good interlocking between these particles and the geogrid apertures, but certainly also depending on other grid and fill properties and characteristics. In the present work it was not possible to assess whether $\theta$ varied during the entire test duration, including both the first and second loading stages.

The variations of loading spread angles $(\theta)$ with geogrid tensile stiffness and geogrid ASM are depicted in Fig. 13a, b. The general trend is of $\theta$ increasing with $J_{5 \%}$, but with significant scatter (Fig. 13a). However, no clear trend can be observed in the variation of $\theta$ with ASM in Fig. 13b. 
Because GPF incorporates different geogrid properties, a good exercise would be to verify how $\theta$ would vary with GPF. This variation is presented in Fig. 14, where a general increase in $\theta$ with GPF can be noted, but also with significant scatter. This large scatter may be a consequence of GPF not being capable of capturing all the influences on the value of $\theta$ as well as due to some level of inaccuracy in the measurement of that angle.

\section{Conclusions}

This paper has investigated the influence of reinforcement properties on the performance of low reinforced and unreinforced fills on a compressible subgrade with reference to the behaviour of the fill after surface (rut) maintenance. Geogrids with different geometrical and mechanical properties and a woven geotextile were tested. The main results obtained are summarized below.

The presence of the geosynthetic reinforcement can improve the performance of the fill in the first and second (after maintenance) loading stages. Maximum values of traffic benefit ratio (TBR) of 121 and 48 were obtained for the first loading stage and after surface maintenance, respectively.

The results obtained showed some correlation between fill performance in terms of TBR after surface maintenance and the reinforcement tensile stiffness, but no correlation between the former and the geogrid ASM. Similar to what was observed by Palmeira and Góngora [27], correlation was also found between TBR and a dimensionless geogrid property factor (GPF) after surface maintenance, but with larger scatter than that obtained for the first loading stage.

A general trend of less fill particle breakage and greater load spreading angles with increasing geogrid tensile stiffness was identified. It was also noticed that the intensity of fill particle breakage and the value of the load spreading angle depended on the ratio between geogrid aperture dimension and fill particle diameter. Optimum ranges of variation of the ratio between equivalent geogrid aperture dimension and maximum fill particle diameter were identified where less particle breakage and higher load spreading angles were obtained.

The results presented in the present work suggest that the specification of a geogrid reinforcement for a low fill layer on compressible ground based on its tensile stiffness is necessary but not sufficient. Geogrid thickness, fraction of the grid transverse members available for bearing and the ratio between grid aperture dimensions and fill particles dimension may play important roles on fill performance, life and costs associated with maintenance works. Due to several similarities, the conclusions obtained in the present work may be applicable to some extent to the case of geogrid reinforced unpaved roads, railway tracks and paved roads. However, further research is needed to give a better understanding on the influence of soil-reinforcement interaction on the performance of reinforced fills on compressible subgrades.

Acknowledgments The authors are indebted to the following institutions for their contributions to the research programme described in this paper: The University of Brasilia, CNPq-National Council for Scientific and Technological Development, Capes/ Brazilian Ministry of Education, FAP/DF-Federal District Foundation for Research Support and the geogrid manufacturers.

\section{References}

1. Palmeira EM, Antunes LGS (2010) Large scale tests on geosynthetic reinforced unpaved roads subjected to surface maintenance. Geotext Geomembr 28:547-558

2. Steward J, Williamson R, Mahoney J (1977) Guidelines for use of fabrics in construction and maintenance of low-volume roads. Report PB-276 972, Forest Service, USDA, Portland, Oregon, USA

3. Palmeira EM (1981) Geotextiles as reinforcement of embankments on soft soils. MSc Thesis, Federal University of Rio de Janeiro, Brazil, $282 \mathrm{p}$ (in Portuguese)

4. Ramalho-Ortigao JAR, Palmeira EM (1982) Geotextile performance at an access road on soft ground near Rio de Janeiro. In: 2nd international conference on geosynthetics, vol 1. IFAI, St. Paul, Minnesota, USA, pp 353-358

5. Love JT, Burd HJ, Milligan GWE, Houlsby GT (1987) Analytical and model studies of reinforcement of a granular layer on a soft clay subgrade. Can Geotech J 24:611-622

6. Hufenus R, Rueegger R, Banjac R, Mayor P, Springman SM, Brönnimann R (2006) Full-scale field tests on geosynthetic reinforced unpaved roads on soft subgrade. Geotext Geomembr 24(1):21-37

7. Sigurdson O (1993) Geosynthetic stabilization of unpaved roads on soft ground: a field evaluation. M.A.Sc. Thesis, University of British Columbia, BC, Canada

8. Góngora AG, Palmeira EM (2012) Influence of fill and geogrid characteristics on the performance of unpaved roads on weak subgrades. Geosynth Int 19(2):191-199

9. Burd HJ (1986) A large displacement finite element analysis of a reinforced unpaved road. D.Phil. Thesis, University of Oxford, UK

10. Burd HJ, Houlsby GT (1989) Numerical modelling of reinforced unpaved roads. In: Proceedings of 3rd international symposium on numerical models in geomechanics, vol 1. Niagara, Canada, pp 699-706

11. Brocklehurst CJ (1993) Finite element studies of reinforced and unreinforced two-layer soil systems. DPhil. Thesis, University of Oxford, UK

12. Burd HJ, Brocklehurst CJ (1994) Finite element studies of the mechanics of reinforced unpaved roads. In: Proceedings of the 4th international conference on geosynthetics, vol 1. The Hague, The Netherlands, pp 217-221

13. Leng J, Gabr MA (2005) Numerical analysis of stress-deformation response in reinforced unpaved road sections. Geosynth Int 12(2):111-119

14. Jessberger HL (1977) Load-bearing behaviour of a gravel subbase-non-woven fabric-soft subgrade system. In: Proceedings of the international conference on the use of fabrics in geotechnics, vol 1. Paris, France, pp 9-13 
15. Nieuwenhuis JD (1977) Membranes and the bearing capacity of road bases. In: Proceedings of the international conference on the use of fabrics in geotechnics, vol 1. Paris, France, pp 3-8

16. Giroud JP, Noiray L (1981) Geotextile-reinforced unpaved road design. ASCE J Geotech Eng 107(9):1233-1254

17. Houlsby GT, Jewell RA (1990) Design of reinforced unpaved roads for small rut depths. In: Proceedings of the 4th international conference on geosynthetics, vol 1. The Hague, The Netherlands, pp 171-176

18. Giroud JP, Han J (2004) Design method for geogrid-reinforced unpaved roads. I: development of design method. ASCE J Geotech Geoenviron Eng 130(8):775-786

19. Palmeira EM, Cunha MG (1993) A study on the mechanics of unpaved roads with reference to the effects of surface maintenance. Geotext Geomembr 12:109-131

20. Palmeira EM, Ferreira LG (1994) The behaviour of unpaved roads under large rutting conditions. In: International conference on geotextiles geomembranes and related products, vol 1. Singapore, pp 135-138

21. Palmeira EM (1998) Geosynthetic reinforced unpaved roads on very soft soils: construction and maintenance effects. In: Proceedings of 6th international conference on geosynthetics, vol 2. IGS/IFAI, Atlanta, USA, pp 885-890

22. Góngora IAG (2015) Geosynthetic reinforced unpaved roads: influence of physical and mechanical properties of the reinforcement. PhD. Thesis, Graduate Programme of Geotechnics, University of Brasilia, Brazil (in Portuguese)

23. Cancelli A, Montanelli F, Rimoldi P, Zhao A (1996) Full scale laboratory testing on geosynthetics reinforced paved roads. In: Proceedings of international symposium on earth reinforcementIS Kyushu'96, vol 1. Fukuoka, Kyushu, Japan, pp 573-578

24. Brown SF, Kwan J, Thom NH (2007) Identifying the key parameters that influence geogrid reinforcement of railway ballast. Geotext Geomembr 25(6):326-335

25. Hussaini SKK (2012) An experimental study on the deformation behaviour of geosynthetic reinforced ballast. $\mathrm{PhD}$. Thesis, University of Wollongong, Australia

26. Kinney TC, Xiaolin Y (1995) Geogrid aperture rigidity by in-plane rotation. In: Proceedings of geosynthetics'95, vol 2. Nashville, Tennessee, USA, pp 525-537
27. Palmeira EM, Góngora IAG (2015) Assessing the influence of soil-reinforcement interaction parameters on the performance of a low fill on compressible subgrade-part I: fill performance and relevance of interaction parameters. Int J Geosynth Ground Eng. doi:10.1007/s40891-015-0041-3

28. Cancelli A, Montanelli F (1999) In-ground tests for geosynthetic reinforced flexible paved roads. In: Proceedings of geosynthetics'99, vol 2. Boston, Massachusetts, USA, pp 863-878

29. Perkins SW (2001) Mechanistic-empirical modeling and design model development of geosynthetic reinforced flexible pavements: final report. Report No. FHWA/MT-01-002/991601A, State of Montana Department of Transportation/Federal Highway Administration, USA

30. Perkins SW, Ismeik M, Fogelsong ML (1999) Influence of geosynthetic placement position on the performance of reinforced flexible pavement systems. In: Proceedings of geosynthetics'99, vol 1. Boston, USA, pp 253-264

31. Sprague J (2001) In-plane rotational stiffness (A.K.A. torsional rigidity). TRI/Environmental Lab Updates, vol 1, issue 1. www. geosynthetica.net/resources/inplane-rotational-stiffness-aka-tor sional-rigidity/

32. Tang X (2011) A study of permanent deformation behaviour of geogrid reinforced flexible pavements using small scale accelerated pavement testing. PhD. Thesis, Pennsylvania State University, Pennsylvania, USA

33. Tang X, Chehab GR, Palomino A (2008) Evaluation of geogrids for stabilising weak pavement subgrade. Int $\mathrm{J}$ Pavement Eng 9(6):413-429

34. Cuelho E, Perkins S, Morris Z (2014) Relative operational performance of geosynthetic used as subgrade stabilization. Final Project Report, FHWA/MT-14-002/7712-251, Research Programs, State of Montana Department of Transportation, Montana, USA

35. Marsal RJ (1973) Mechanical properties of rockfill. In: Hirschfeld RC, Poulos SJ (eds) Embankment dam engineering - Casagrande volume. Wiley, New York, pp 109-200 